\title{
Early exposure to thimerosal-containing vaccines and children's cognitive development. A 9-year prospective birth cohort study in Poland
}

\author{
Dorota Mrozek-Budzyn • Renata Majewska • \\ Agnieszka Kieltyka
}

Received: 10 June 2014 /Revised: 18 August 2014 / Accepted: 25 August 2014 /Published online: 5 September 2014

(C) The Author(s) 2014. This article is published with open access at Springerlink.com

\begin{abstract}
The controversial topic of the early exposure to mercury is regarding ethylmercury, which is present in the thimerosal-containing vaccines (TCVs). The objective of this study was to determine the relationship between the early exposure to TCVs and cognitive development in children during the first 9 years of life. The cohort included 318 children vaccinated in an early period (neonatal and up to 6 months) against hepatitis $\mathrm{B}$ and diphtheria-tetanus-pertussis (DTP) using formulation with or without thimerosal. The children's development was assessed using the Fagan test (6th month of life), the Bayley Scales of Infant Development (BSID)-II (12th-36th month), the Raven test (5th, 8th year), and the Wechsler Intelligence Scale for Children (WISC-R) (6th, 7th, 9th year). Results were determined by multivariable linear and logistic regression, adjusted to potential confounders. Children exposed and not exposed to TCVs in the neonatal period had similar outcomes of cognitivedevelopmental tests; only the results of BSID-II at the 36th month and WISC-R at the 9th year were significantly higher for those exposed to TCVs. Developmental test results in children exposed to TCVs up to the 6th month of life also did not depend on thimerosal dose.

Conclusion: TCV administration in early infancy did not affect children's cognitive development.
\end{abstract}

\footnotetext{
Communicated by Peter de Winter

D. Mrozek-Budzyn $(\square) \cdot$ R. Majewska $\cdot$ A. Kiełtyka

Department of Epidemiology, Chair of Epidemiology and Preventive

Medicine, Jagiellonian University Medical College, Kopernika 7a St,

31-034 Krakow, Poland

e-mail: dorota.mrozek-budzyn@uj.edu.pl

R. Majewska

e-mail: rmajewska@cm-uj.krakow.pl

A. Kieltyka

e-mail: mykielty@cyf-kr.edu.pl
}

Keywords Ethylmercury $\cdot$ Vaccines $\cdot$ Children · Developmental outcomes

$\begin{array}{ll}\text { Abbreviations } \\ \text { BSID-II } & \begin{array}{l}\text { Bayley Scales of Infant Development-Second } \\ \text { Edition }\end{array} \\ \text { DTP } & \text { Diphtheria-tetanus-pertussis } \\ \text { FTII } & \text { Fagan Test of Infant Intelligence } \\ \text { ETS } & \text { Environmental tobacco smoke } \\ \text { MDI } & \text { Mental Development Index of BSID-II } \\ \text { TONI-3 } & \text { Test of Nonverbal Intelligence, Third Edition } \\ \text { TCVs } & \text { Thimerosal-containing vaccines } \\ \text { WISC-R } & \text { Wechsler Intelligence Scale for } \\ & \text { Children-Revised }\end{array}$

Introduction

High doses of mercuric compounds are nephrotoxic and neurotoxic. Cumulative exposure to an organic mercurycontaining compound, methylmercury, can also produce neurologic and renal damage. It has a long half-life and can cross the blood-brain barrier, where it accumulates and is converted to inorganic mercury [16]. Ethylmercury, a related organic mercury compound, is a constituent of thimerosal, an antibacterial agent used in certain non-live vaccines. Ethylmercury has a much shorter half-life than methylmercury, being rapidly excreted via stools after parenteral administration, but its influence on children's health has not been determined yet $[18,19]$. Nevertheless, the guidelines to limit cumulative methylmercury exposure have been translated to ethylmercury.

The discussion on the safety of thimerosal-containing vaccines (TCVs) started in 1999 (Joint Statement issued by the American Academy of Pediatrics and the US 
Public Health Service in July 1999) [11]. It was suspected that ethylmercury contained in the vaccines had a harmful effect on children's neurodevelopment. In fact, the low-dose human exposure to ethylmercury has not been assessed sufficiently, although it is assumed to have a similar effect as the exposure to methylmercury that demonstrated harmful consequences $[6,7,9]$. Since 2004, no vaccines recommended and routinely used in the USA and the European Union to protect preschool children have contained thimerosal $[4,20]$. Nevertheless, most countries continue to use TCVs in their childhood immunization schedules.

The objective of this study was to determine the relationship between the early exposure to TCVs and cognitive development in children up to the 9th year of life.

\section{Material and methods}

This is a prospective cohort study, combining environmental monitoring and molecular approaches with comprehensive neurodevelopment assessments. In the analysis, we used data on the vulnerability of a fetus and child to environmental factors, coming from an earlier established birth cohort of children in Krakow, being part of an ongoing, collaborative study together with Columbia University in New York. The study has received the approval of the Jagiellonian University Ethical Committee (Krakow, Poland).

The enrolment (November 3, 2000-August 22, 2003) included only non-smoking women, aged 18-35 years, with singleton pregnancy without illicit drug use and HIV infection, free from chronic diseases such as diabetes or hypertension, and residing in Krakow for at least 1 year prior to the pregnancy. The infants were followed up to the 9th year of life. Each year, mothers were asked to provide information on infants' health and household characteristics by trained interviewers, who carried out detailed, face-to-face standardized interviews. The Test of Nonverbal Intelligence, Third Edition (TONI-3) was administered to mothers. We have included this instrument to adjust to the maternal contribution to the child's cognitive development.

\section{Vaccination data}

The data on infants' vaccination history (date of vaccination and type of vaccine) were extracted from the physician's records. Neonatal thimerosal exposure status was based on hepatitis B vaccination in the first 29 days of life (first dose). A further level of TCV exposure took into consideration hepatitis $\mathrm{B}$ as well as diphtheria-tetanus-pertussis (DTPw or DTPa) vaccines up to the 6 th month of life.
Biological samples and analysis

Heavy metal (mercury, lead) concentrations were examined in cord blood (at delivery) and capillary blood (5-year-old children). Whole blood lead concentrations were determined using inductively coupled plasma mass spectrometry CLIA' 88 method "Blood lead cadmium mercury ICPMS_ITB001A." This multielement analytical technique is based on quadruple ICP-MS technology [3]. Mercury levels were measured at the Center for Disease Control by Zeeman graphite furnace atomic absorption spectrometry, using a phosphate/Triton X-100/ nitric acid matrix modifier. Cold vapor atomic spectrometry following chemical reduction of mercury compounds was used to measure total mercury in whole blood. More details on blood sample collection and analysis were presented in the earlier publications $[9,10]$.

\section{Infant neurodevelopment testing}

The Fagan Test of Infant Intelligence (FTII) was conducted at the 6th month of life. The Bayley Scales of Infant Development, Second Edition (BSID-II) was administered at the 12th, 24th, and 36th month of life. The Mental Scale of BSID_II test includes items that assess memory, habituation, problem solving, early number concepts, generalization, classification, vocalization, language, and social skills [2]. Test scores are adjusted to the child's age to obtain the Mental Development Index (MDI). Test results are in one of four categories: (1) accelerated performance (score $>115$ ), (2) within normal limits (score 85 to 114), (3) mildly delayed performance (score 70 to 84 ), and (4) significantly delayed (score $<69$ ). Results $<85$ were considered as poorer cognitive development.

The test of Raven's Colored Progressive Matrices (Raven) was administered twice, at the 5th and 8th year of life. The outcomes of the test were measured in terms of centiles. Because the results of this test were generally high, the cut point of poor result category was 75th percentile, which means middle intelligence outcomes.

The Wechsler Intelligence Scale for Children-Revised (WISC-R) was administered at the 6th, 7th, and 9th year of life and generated verbal, non-verbal, and total IQ for the evaluated children. The outcome's range is from 40 to 160 . The category with IQ $<110$ was considered as the poorer outcomes.

All neurodevelopment tests were conducted at the Department of Epidemiology and Preventive Medicine by carefully trained examiners who were unaware of the child's exposure. The Bayley Scales as well as the Raven test have well-defined criteria and were considered as fully consent between the different examiners. In order to provide a fully comparable assessment of the WISC-R test, one psychologist rated performed answers for all the children. 


\section{Confounders}

Data on possible confounders such as maternal age (continuous variable) and education (university vs. non-university); maternal non-verbal intelligence (result of the TONI-3 as a continuous variable); older siblings (yes or no); exposure to passive tobacco smoking during pregnancy (yes or no); child's gender, gestational age ( $\geq 37$ vs. $<37$ weeks), birth weight (continuous variable, unit $100 \mathrm{~g}$ ), Apgar score, blood mercury and lead level (cord and at the age of 5), breastfeeding (children breastfed for at least 6 months), and exposure to ethylmercury in later life (from the 29th day to the 6th month) were collected and included in the analysis.

\section{Statistical analysis}

In the descriptive analysis, differences in the distribution of women and newborns' parameters grouped by thimerosal vaccination status were tested using $\chi^{2}$ (for nominal variables) and the Mann-Whitney and Kruskal-Wallis tests (for continuous variables).

The comparison of the test outcomes according to the exposure to the type of vaccine (TCVs vs. non-TCVvaccinated group) was studied using multivariate linear models. The logistic models were used to assess risk of poorer developmental outcomes (MDI $<85$, Raven $<75$, IQ $<110$ ) as well. All variables from Table 1 showing a probable association with thimerosal vaccination status $(p<0.1)$ were included in statistical multivariable models. Blood lead level at the age of 5 was used as a confounder in models for 5-year-old and older children. Additionally, the child's gender was added to all models as it is highly associated with developmental tests' performance.

Statistical analyses were performed using STATA software version 12.1.

\section{Results}

The analyzed population consisted of 318 children: $52.8 \%$ boys and $47.2 \%$ girls. One child from that group $(0.3 \%)$ was absent during FTII and BSID-II test at the 12th month. In that group, retention rate during psychological tests in further years was $97.5 \%$ at $2 \mathrm{nd}, 94.7 \%$ at $3 \mathrm{rd}, 78.3 \%$ at 5 th, $60.7 \%$ at 6 th, $67.9 \%$ at 7 th, $55.0 \%$ at 8 th, and $64.8 \%$ at 9 th with reference to the initial cohort, respectively. Retention rates were comparable between studied groups.

In the analyzed group, all but one child were vaccinated against hepatitis B in the neonatal period, $220(69.2 \%)$ of them with TCVs. Ninety-eight (30.8\%) children were vaccinated with thimerosal-free Engerix B, $162(50.9 \%)$ with Euvax B, and $58(18.2 \%)$ with Hepavax-Gene, the latter two containing $25 \mu \mathrm{g}$ thimerosal per dose. Most of the children $(302,95.0 \%)$ were vaccinated within 1 day after birth and an additional nine (totally $97.8 \%$ ) within 1 week.

Exposure to TCVs up to the age of 6 months was connected with further doses of hepatitis B and DTPw/DTPa vaccines administered according to the Polish immunization schedule. The children were vaccinated with DTPw vaccine with thimerosal $(25 \mu \mathrm{g} / \mathrm{dose})$ manufactured in Poland and thimerosalfree vaccines (DTPa), such as Infanrix IPV+Hib, Infanrix Hexa, Tripacel, and Tetracoq. All the analyzed vaccines (thimerosal-containing and thimerosal-free) contained aluminum compounds as adjuvant.

Between the 29th day and the 6th month of life, $86.2 \%$ of children were vaccinated with TCVs. The children immunized with ethylmercury-containing vaccines in the neonatal period were more frequently vaccinated with ethylmercury later in their life compared to those not immunized with TCVs $(92.3$ vs. $72.4 \%, p<0.001)$. Figure 1 presents the distribution of exposure to TCVs in the period of the first 6 months of life.

Neonatal exposure to TCVs was derived from hepatitis B vaccine only which was mainly administrated in the first $24 \mathrm{~h}$ after delivery. It was dependent on the decision of the Ministry of Health, who decided about the kind of vaccine (cheaper or more expensive) secured for all children in Poland at the same period of time. In the group of children examined, those born in 2001 were vaccinated almost only $(89.2 \%)$ with thimerosal-free vaccines, while those born in 2002-2004 with TCV (96.8 \%) in the neonatal period. This vaccination was independent of parents' decision. No significant differences were found for maternal characteristics such as age, education, and the TONI-3 scores, between the children exposed and non-exposed to TCVs in the neonatal period. Passive tobacco smoking during pregnancy was less common among the mothers of children from the neonatal TCV group (32.7 vs. $48.0 \%, p=0.010)$. On the other hand, further exposure to TCVs depended partly on the Ministry of Health decision and partly on family socioeconomic status that can be seen in significant differences in maternal and paternal education levels (Table 1). Also, prematurely born children were less often vaccinated with TCV.

As for child characteristics, only the lead level in cord blood was significantly lower in the TCV-exposed group than in the non-exposed one $(1.3$ vs. $1.7 \mu \mathrm{g} / \mathrm{dL}, p<0.001$, for exposure in the neonatal period and 1.3, 1.4, and $1.7 \mu \mathrm{g} / \mathrm{dL}$ in the 6-month period) (Table 1).

The outcomes of cognitive development

The results of psychological tests verifying children's cognitive development were mostly on the same level in groups exposed and non-exposed to TCVs in both neonatal and 6month periods, which were presented in Fig. 2a, b. The significant differences among exposures in the neonatal period 
Table 1 Characteristics of the study subjects by neonatal and 6-month ethylmercury exposure

\begin{tabular}{|c|c|c|c|c|c|c|c|c|c|c|c|c|}
\hline & \multicolumn{5}{|c|}{ Neonatal exposure to TCV } & \multicolumn{7}{|c|}{ Thimerosal exposure up to 6 months } \\
\hline & \multicolumn{2}{|c|}{$\begin{array}{l}\text { Non-exposed } \\
(N=98)\end{array}$} & \multicolumn{2}{|c|}{$\begin{array}{l}\text { Exposed } \\
(N=220)\end{array}$} & \multirow[t]{2}{*}{$p$} & \multicolumn{2}{|c|}{$\begin{array}{l}\text { No exposure } \\
(N=27)\end{array}$} & \multicolumn{2}{|c|}{$\begin{array}{l}\text { From } 25 \text { to } \\
50 \mu \mathrm{g}(N=117)\end{array}$} & \multicolumn{2}{|c|}{$\begin{array}{l}\text { Above } 50 \mu \mathrm{g} \\
(N=174)\end{array}$} & \multirow[t]{2}{*}{$p$} \\
\hline & $N$ & $\%$ & $N$ & $\%$ & & $N$ & $\%$ & $N$ & $\%$ & $N$ & $\%$ & \\
\hline Maternal education level & & & & & 0.536 & & & & & & & \\
\hline Elementary/ vocational school & 11 & 11.2 & 17 & 7.7 & & 1 & 3.7 & 4 & 3.4 & 23 & 13.2 & 0.009 \\
\hline High school & 39 & 39.8 & 85 & 38.6 & & 10 & 37.0 & 41 & 35.0 & 73 & 42.0 & \\
\hline University & 48 & 49.0 & 118 & 53.6 & & 16 & 59.3 & 72 & 61.5 & 78 & 44.8 & \\
\hline Maternal marital status & 90 & 91.8 & 209 & 95.0 & 0.272 & 26 & 96.3 & 111 & 94.9 & 162 & 93.1 & 0.719 \\
\hline Poor economical status & 4 & 4.1 & 20 & 9.1 & 0.118 & 0 & - & 7 & 6.0 & 17 & 9.8 & 0.146 \\
\hline Paternal education & & & & & 0.985 & & & & & & & \\
\hline Elementary/ vocational school & 12 & 13.0 & 27 & 13.4 & & 2 & 7.7 & 7 & 6.7 & 30 & 18.4 & 0.006 \\
\hline High school & 28 & 30.4 & 63 & 31.2 & & 5 & 19.2 & 30 & 28.6 & 56 & 34.4 & \\
\hline University & 52 & 56.5 & 112 & 55.4 & & 19 & 73.1 & 68 & 64.8 & 77 & 47.2 & \\
\hline Passive tobacco smoking during pregnancy & 47 & 48.0 & 72 & 32.7 & 0.010 & 14 & 51.9 & 31 & 26.5 & 74 & 42.5 & 0.006 \\
\hline Boys & 49 & 50.0 & 119 & 54.1 & 0.500 & 16 & 59.3 & 65 & 55.6 & 87 & 50.0 & 0.508 \\
\hline Gestational age $<37$ weeks & 4 & 4.1 & 7 & 3.2 & 0.743 & 3 & 11.1 & 8 & 6.8 & 0 & - & $<0.001$ \\
\hline Older siblings & 40 & 40.8 & 78 & 35.5 & 0.361 & 9 & 33.3 & 42 & 35.9 & 67 & 38.5 & 0.825 \\
\hline Breastfeeding up to 6 months & 71 & 72.4 & 154 & 70.0 & 0.658 & 19 & 70.4 & 86 & 73.5 & 120 & 69.0 & 0.705 \\
\hline \multirow[t]{2}{*}{ Passive tobacco smoking during 5 years } & 16 & 19.5 & 54 & 28.7 & 0.112 & 3 & 12.5 & 20 & 21.1 & 47 & 31.1 & 0.062 \\
\hline & Mean & SD & Mean & $\mathrm{SD}$ & & Mean & $\mathrm{SD}$ & Mean & $\mathrm{SD}$ & Mean & SD & \\
\hline Mother's age at the 2 nd trimester & 27.5 & 3.84 & 27.6 & 3.52 & 0.907 & 28.3 & 3.94 & 28.0 & 3.31 & 27.1 & 3.73 & 0.073 \\
\hline Maternal non-verbal intelligence (TONI-3) & 105.7 & 19.06 & 110.3 & 17.04 & 0.082 & 108.3 & 20.39 & 110.0 & 17.77 & 108.6 & 17.36 & 0.834 \\
\hline Birth weight $[\mathrm{g}]$ & 3391.5 & 531.52 & 3412.4 & 469.47 & 0.726 & 3206.3 & 637.80 & 3391.0 & 518.85 & 3447.0 & 433.44 & 0.053 \\
\hline Head circumference at birth $[\mathrm{cm}]$ & 33.9 & 1.65 & 33.8 & 1.44 & 0.962 & 33.3 & 1.88 & 33.9 & 1.52 & 33.9 & 1.42 & 0.404 \\
\hline Cord blood mercury level $[\mu \mathrm{g} / \mathrm{L}]$ & 0.9 & 0.44 & 1.0 & 0.68 & 0.300 & 1.0 & 0.57 & 1.1 & 0.76 & 1.0 & 0.56 & 0.570 \\
\hline Cord blood lead level $[\mu \mathrm{g} / \mathrm{dL}]$ & 1.7 & 0.91 & 1.3 & 0.49 & $<0.001$ & 1.7 & 0.65 & 1.3 & 0.65 & 1.4 & 0.67 & 0.001 \\
\hline Blood mercury level $[\mu \mathrm{g} / \mathrm{L}]$ & 2.1 & 0.67 & 2.2 & 0.74 & 0.056 & 2.0 & 0.59 & 2.1 & 0.81 & 2.2 & 0.68 & 0.409 \\
\hline Blood lead level $[\mu \mathrm{g} / \mathrm{dL}]$ & 0.6 & 0.26 & 0.5 & 0.32 & 0.224 & 0.6 & 0.33 & 0.6 & 0.31 & 0.5 & 0.30 & 0.495 \\
\hline
\end{tabular}

$S D$ standard deviation, $p$ significance level

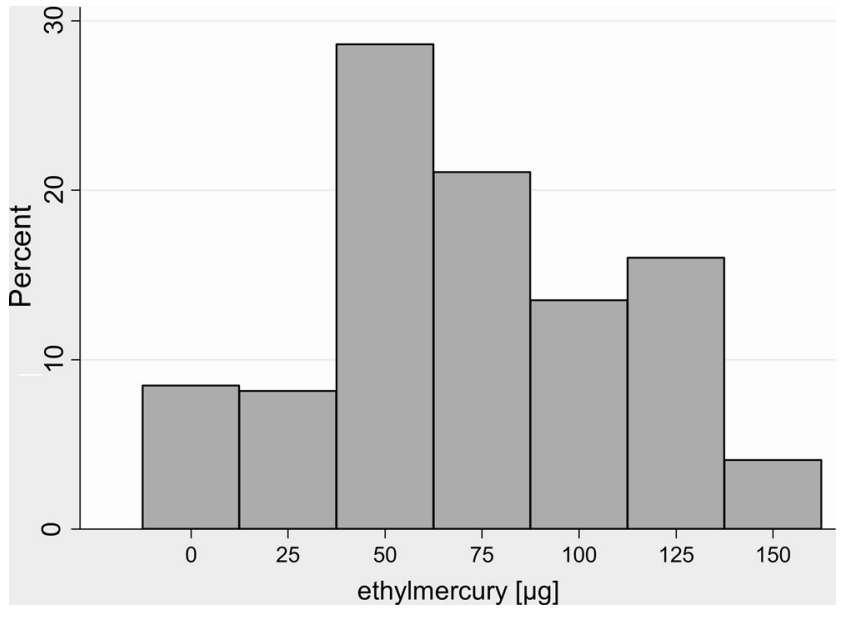

Fig. 1 Distribution of ethylmercury doses in the 6-month period were observed in the Fagan (58.5 vs $61.2, p=0.002$ ), the MDI at the 36th month (101.6 vs 104.6, $p=0.024)$, and the WISC-R at the 9 th year according to verbal ( $69.0 \mathrm{vs} 73.0, p=0.003)$ and total (125.4 vs $130.4, p=0.005)$ IQ levels, which were higher in the TCV-exposed groups. After standardization to child's gender, mother's higher education, prenatal ETS, breastfeeding up to 6 months, $\mathrm{Hg}$ in cord blood, as well as the exposure to thimerosal from the 29th day up to the 6th month, only the MDI of the BSID-II $(\beta=4.10, p=0.016)$ and the WISC-R ( $\beta=3.96, p=0.040$ for verbal IQ, and $\beta=4.73$, $p=0.049$ for overall IQ) differences remained significant (Table 2). All developmental tests performed from the 5th to 9th year were additionally standardized to blood mercury level which was measured when children were 5 years old. Significant differences in the MDI levels observed at the age of 12 months connected with thimerosal exposure during 6 months after birth were observed only in univariate analysis 


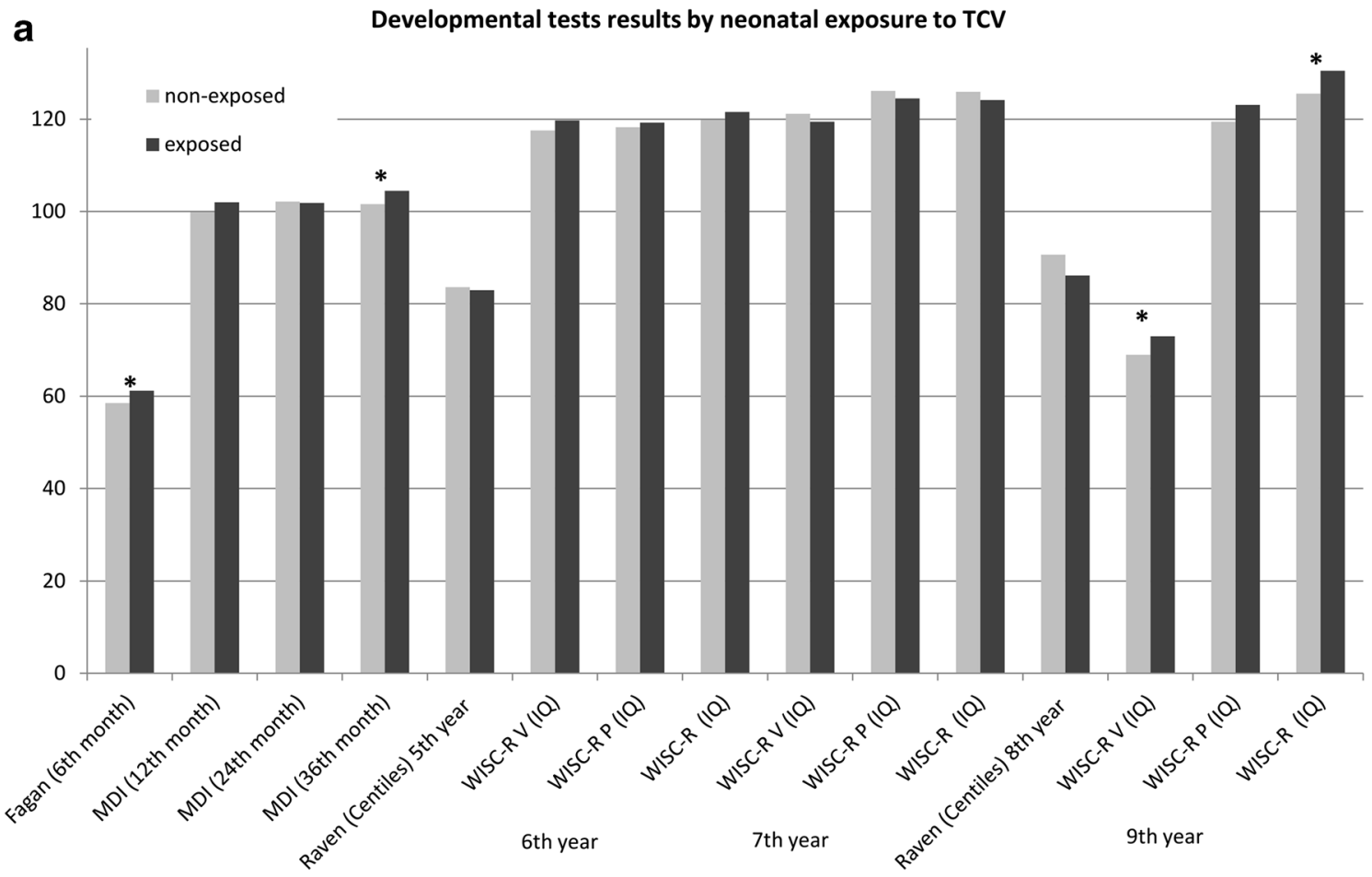

\section{b Developmental tests results by 6 months ethylmercury exposure}

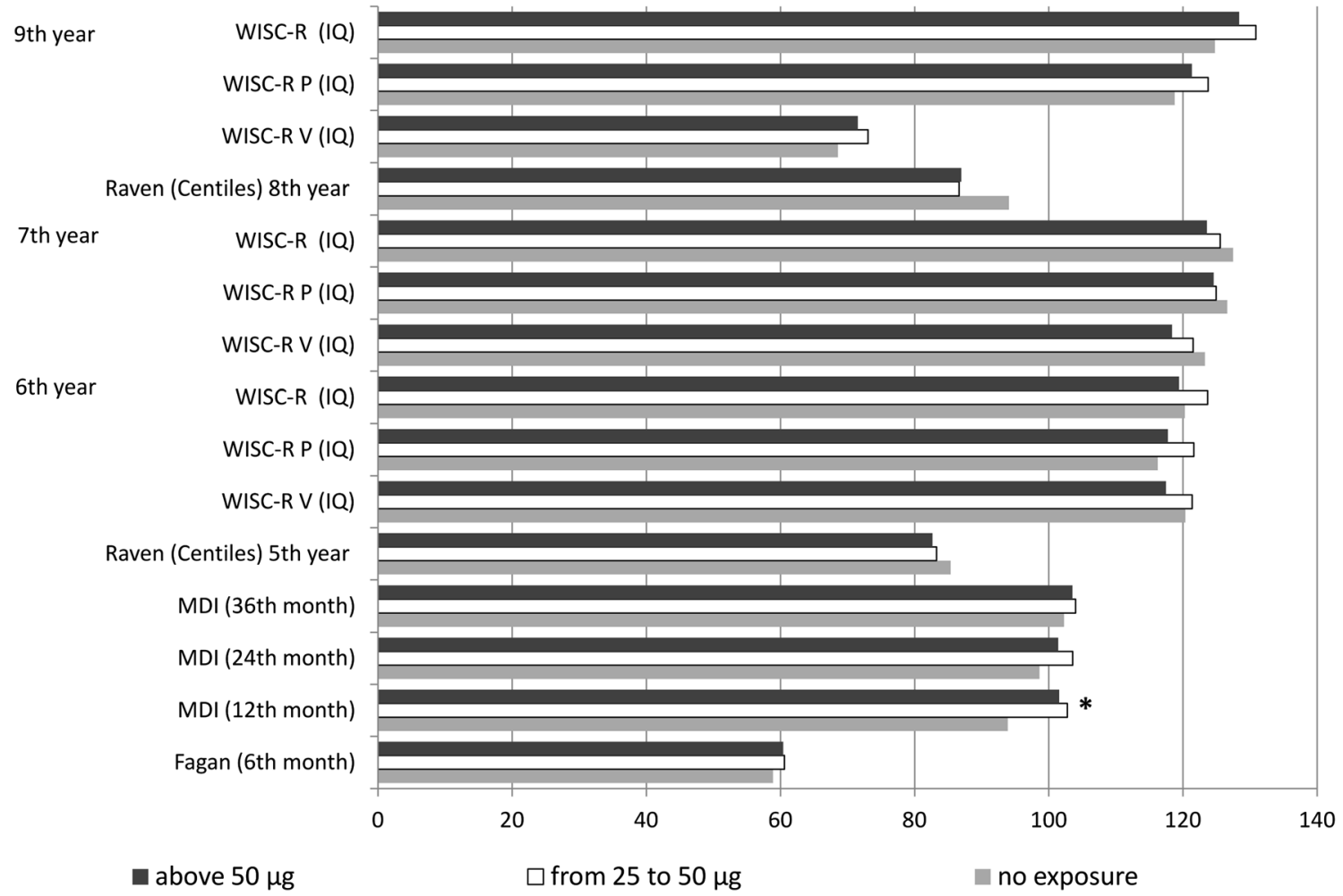

Fig. 2 Average development test scores in the ethylmercury-exposed and non-exposed groups in the a) neonatal b) 6 month period. * $p<0.05$. $M D I$ Mental Development Index of BSID-II, WISC- $R V$ WISC-R verbal scale, WISC- $R$ P WISC-R performance scale 
Table 2 The association between ethylmercury exposure and developmental test scores up to 9 years of age

\begin{tabular}{|c|c|c|c|c|c|c|c|}
\hline \multirow[t]{2}{*}{ Test } & \multirow[t]{2}{*}{ Age } & \multicolumn{3}{|c|}{ Neonatal exposure $^{\mathrm{a}}$} & \multicolumn{3}{|c|}{ 6-month exposure ${ }^{b}$} \\
\hline & & Beta & $p$ & $95 \% \mathrm{CI}$ & Beta & $p$ & $95 \%$ CI \\
\hline FTII & 6th month & 1.38 & 0.248 & $-0.97-3.72$ & 0.14 & 0.632 & $-0.43-0.70$ \\
\hline MDI of BSID-II & 12th month of life & 2.09 & 0.220 & $-1.26-5.44$ & -0.09 & 0.825 & $-0.90-0.71$ \\
\hline MDI of BSID-II & 24th month of life & -2.00 & 0.337 & $-6.08-2.09$ & -0.48 & 0.343 & $-1.46-0.51$ \\
\hline MDI of BSID-II & 36th month of life & 4.10 & 0.016 & $0.76-7.43$ & 0.78 & 0.060 & $-0.31-1.58$ \\
\hline Raven (centiles) & 5th year of life & -0.29 & 0.937 & $-7.50-6.92$ & -0.77 & 0.619 & $-2.45-0.92$ \\
\hline WISC-R & 6th year of life & & & & & & \\
\hline Verbal IQ ${ }^{c}$ & & 2.32 & 0.399 & $-3.12-7.76$ & -0.62 & 0.337 & $-2.01-0.77$ \\
\hline Non-verbal IQ ${ }^{c}$ & & 3.31 & 0.279 & $-2.72-9.35$ & -0.70 & 0.374 & $-2.24-0.85$ \\
\hline $\mathrm{IQ}^{\mathrm{c}}$ & & 2.98 & 0.256 & $-2.19-8.15$ & -0.73 & 0.273 & $-2.05-0.59$ \\
\hline WISC-R & 7th year of life & & & & & & \\
\hline Verbal $\mathrm{IQ}^{\mathrm{c}}$ & & -1.66 & 0.513 & $-6.65-3.34$ & -1.12 & 0.265 & $-1.88-0.52$ \\
\hline Non-verbal IQ ${ }^{\mathrm{c}}$ & & -0.72 & 0.802 & $-6.41-4.96$ & 0.43 & 0.534 & $-0.94-1.80$ \\
\hline $\mathrm{IQ}^{\mathrm{c}}$ & & -1.33 & 0.560 & $-5.87-3.19$ & -0.14 & 0.805 & $-1.23-0.96$ \\
\hline Raven (centiles) & 8th year of life & -3.40 & 0.325 & $-10.22-3.42$ & -0.35 & 0.691 & $-2.09-1.39$ \\
\hline WISC-R & 9th year of life & & & & & & \\
\hline Verbal $\mathrm{IQ}^{\mathrm{c}}$ & & 3.96 & 0.040 & $0.18-7.75$ & 0.02 & 0.963 & $-0.99-1.04$ \\
\hline Non-verbal IQ ${ }^{c}$ & & 3.20 & 0.214 & $-1.87-8.27$ & -0.71 & 0.285 & $-2.02-0.60$ \\
\hline $\mathrm{IQ}^{\mathrm{c}}$ & & 4.73 & 0.049 & $0.03-9.44$ & -0.40 & 0.527 & $-1.64-0.84$ \\
\hline
\end{tabular}

${ }^{a}$ Standardized to child's gender, mother's higher education, prenatal ETS, breastfeeding up to 6 months, $\mathrm{Hg}$ in cord blood, as well as exposure to thimerosal from the 29th day up to the 6th month

${ }^{\mathrm{b}}$ Standardized to child's gender, mother's higher education, prenatal ETS, breastfeeding up to 6 months, and dHg in cord blood; exposure to ethylmercury as continuous variable formulated as number of TCV doses

${ }^{\mathrm{c}}$ Additionally standardized to blood $\mathrm{Hg}$ level in 5-year-old children

(93.9, 102.8, and 101.4, $p=0.003$ ). After standardization to the above mentioned variables, they lost their significance $(\beta=-0.09, p=0.825)($ Table 2$)$.

Risk of poorer outcomes in cognitive development

According to assumed criteria, poorer outcomes in MDI results were present in $7.3 \%$ of children at the 1 st year, $9.0 \%$ at the 2 nd year, and $4.3 \%$ at the 3 rd year of life. Poorer outcomes of the Raven test were present in $20.9 \%$ of children tested at the 5 th year of life and $16.6 \%$ of those tested at the 8 th year of life.

WISC-R IQ results less than 110 were observed for 14.5 $22.3 \%$ of 6-year-old, $8.3-17.1 \%$ of 7-year-old, and 3.9$14.1 \%$ of 9 -year-old children. No significant differences were observed in the proportion of children with poorer cognitive test results caused by neonatal TCV exposure in the case of all studied tests, but Raven in the 8th year. Similarly, we did not observe any differences in the proportion of children getting poorer results according to exposure to TCVs in the 6-month period. Multivariable analysis of risk of obtained poorer cognitive results from the 1st to 9th year of life did not show that TCV exposure may affect the studied results (Table 3 ).

\section{Discussion}

We did not find any negative correlation between neonatal and early infancy TCV exposure and mental development in children up to 9 years of age. Our results are consistent with the observations of other authors who did not confirm the influence of TCVs on mental development $[1,8,21]$. On the other hand, some other reports indicated both beneficial and adverse effects of TCVs on children's development [14]. This fact may result from the methodological differences of the epidemiological studies and the time elapsed between the exposure and the development assessment.

The advantage of our study is the long-term, 9-year survey of the cohort with methodological assessment of children's development with an average 1-year interval between the administered tests. Differently from the other authors, we obtained the outcomes of children's mental development after shorter and longer periods of time following early TCV exposure. Hence, we had the possibility to adjust the crude results to many important confounders that could influence development during the first years of life. The strength of the study is the consistency of the lack of association between early TCV exposure and mental development in each stage of life up to 
Table 3 The risk of delay in cognitive development according to ethylmercury exposure

\begin{tabular}{|c|c|c|c|c|c|c|c|}
\hline \multirow[t]{2}{*}{ Test } & \multirow[t]{2}{*}{ Age } & \multicolumn{3}{|c|}{ Neonatal exposure ${ }^{a}$} & \multicolumn{3}{|c|}{ 6-month exposure ${ }^{b}$} \\
\hline & & OR & $p$ & $95 \% \mathrm{CI}$ & OR & $p$ & $95 \% \mathrm{CI}$ \\
\hline MDI of BSID-II & 12th month of life & 0.58 & 0.238 & $0.24-1.42$ & 0.93 & 0.597 & $0.71-1.22$ \\
\hline MDI of BSID-II & 24th month of life & 1.04 & 0.928 & $0.44-1.47$ & 0.98 & 0.873 & $0.76-1.26$ \\
\hline MDI of BSID-II & 36th month of life & 0.56 & 0.341 & $0.17-1.84$ & 0.80 & 0.242 & $0.55-1.16$ \\
\hline Raven (centiles) & 5 th year of life & 0.93 & 0.835 & $0.47-1.84$ & 0.99 & 0.923 & $0.82-1.20$ \\
\hline WISC-R & 6th year of life & & & & & & \\
\hline Verbal IQ $^{\mathrm{c}}$ & & 0.75 & 0.457 & $0.35-1.59$ & 1.15 & 0.216 & $0.92-1.44$ \\
\hline Non-verbal IQ ${ }^{c}$ & & 0.91 & 0.825 & $0.40-2.06$ & 0.97 & 0.968 & $0.79-1.28$ \\
\hline $\mathrm{IQ}^{\mathrm{c}}$ & & 1.16 & 0.736 & $0.47-2.90$ & 0.97 & 0.812 & $0.75-1.26$ \\
\hline WISC-R & 7 th year of life & & & & & & \\
\hline Verbal IQ ${ }^{c}$ & & 0.79 & 0.576 & $0.35-1.78$ & 1.04 & 0.717 & $0.83-1.32$ \\
\hline Non-verbal IQ ${ }^{c}$ & & 0.71 & 0.482 & $0.28-1.83$ & 0.74 & 0.049 & $0.55-1.00$ \\
\hline $\mathrm{IQ}^{\mathrm{c}}$ & & 0.52 & 0.222 & $0.18-1.49$ & 0.81 & 0.231 & $0.57-1.14$ \\
\hline Raven (centiles) ${ }^{\mathrm{c}}$ & 8th year of life & 2.69 & 0.224 & $0.55-13.19$ & 1.07 & 0.609 & $0.83-1.37$ \\
\hline WISC-R & 9th year of life & & & & & & \\
\hline Verbal IQ $^{\mathrm{c}}$ & & 0.45 & 0.076 & $0.19-1.09$ & 1.00 & 0.984 & $0.77-1.30$ \\
\hline Non-verbal IQ ${ }^{c}$ & & 1.04 & 0.952 & $0.28-3.81$ & 0.84 & 0.378 & $0.58-1.23$ \\
\hline $\mathrm{IQ}^{\mathrm{c}}$ & & 0.42 & 0.248 & $0.09-1.84$ & 0.76 & 0.247 & $0.47-1.21$ \\
\hline
\end{tabular}

${ }^{\text {a }}$ Standardized to the child's gender, mother's higher education, prenatal ETS, breastfeeding up to 6 months, as well as exposure to thimerosal from the 29th day up to the 6th month

${ }^{\mathrm{b}}$ Standardized to the child's gender, mother's higher education, prenatal ETS, and breastfeeding up to 6 months; exposure to ethylmercury as continuous variable formulated as number of TCV doses

${ }^{\mathrm{c}}$ Additionally standardized to blood $\mathrm{Hg}$ level in 5-year-old children

the 9th year of life after standardization to many important confounders. This consistency of outcomes during so many years of life gave us strong evidence that early TCV exposure has no harmful influence on later mental development.

The cohort in our study derived from the general population but was different from the other population studies. In our study, the breastfeeding rate at the 6th month was significantly higher compared to that of infants from the other cohorts [12]. On the other hand, there are studies related to thimerosal exposure and neurodevelopment, conducted in a cohort of exclusively breastfed infants [15]. High breastfeeding rate could be one of the reasons that there was no negative influence of early TCV vaccinations on mental development outcomes. This cannot be attributed solely to the protective role of breastfeeding because the development depends on multiple conditions that can eliminate the potential harmful effect of TCV exposure [19]. For example, in our cohort, girls had higher scores of mental development after TCV exposure compared to boys (not statistically significant). This fact could be derived from the protective effect of estrogen in girls and the negative influence of testosterone in boys [5].

The limitation of this analysis is the study cohort which may not be sufficiently representative of the general population. The main purpose of the Krakow Cohort Study was to assess whether the exposure of pregnant women to air pollutants affects future development of their children. To avoid biases from the other harmful factors, the enrollment covered only those pregnant women who were free from selected chronic diseases, smoking, and occupational exposure to chemicals. That made our cohort somewhat healthier than the entire population.

At first, our study was concentrated on TCV vaccinations in newborns, who greatly differ in their birth weight and maturity. These have an influence on ethylmercury toxicokinetics and toxicodynamics [18]. The newborns received different doses of ethylmercury per kilogram of body mass dependent on birth weight. Since immaturity is not a contraindication to hepatitis $\mathrm{B}$ vaccination, nearly all the newborns were vaccinated during the first days of life, independent of their birth weight and gestational age. In our cohort, the representation of newborns born at gestational age $<37$ weeks was relatively smaller compared to the general population. This special population of immature newborns with low and extremely low birth weight requires further studies.

The main strength of our study was a possibility to determine whether there is an association between early TCV 
exposure and mental delays of milder intensity. Most of the previous epidemiological studies were addressed to the links between ethylmercury exposure and more serious potential side effects in children. We revealed, using very precise mental development tests, that there is not even a subclinical harmful effect of early TCV vaccinations on mental development. The other strong point of our study was the active follow-up of pregnant mothers and their children. It gave us a possibility to control many important confounders potentially affecting children's development. An adjustment to mercury exposure - prenatal (cord blood) and blood level at the 5th year of life - was the most important for that analysis. It is a very precise equivalent of mercury derived from the other sources, for example methylmercury from fish consumption that demonstrated harmful consequences on children's neurodevelopment [13, 17]. Additionally, our analysis related to the neonatal period and included adjustment to postneonatal TCV exposure up to the 6th month.

\section{Conclusions}

We found no negative association between neonatal and early infancy TCV exposure and mental development in children up to 9th year of age. The results of our study should not be treated as a supportive argument for continuation of early $\mathrm{TCV}$ exposure if it is economically unnecessary. They may be interpreted as further evidence on the vaccines' safety even if they still contain thimerosal.

Acknowledgments The study received funding from NIEHS R01 grants entitled "Vulnerability of the Fetus/Infant to $\mathrm{PAH}, \mathrm{PM}_{2.5}$ and ETS" and "Developmental effects of early-life exposure to airborne PAH" (R01ES010165 and R01ES015282) and from The Lundin Foundation, The John and Wendy Neu Family Foundation, and The Gladys and Roland Harriman Foundation. Principal investigator Prof. FP Perera and co-investigator Prof. W Jedrychowski are also acknowledged.

Conflict of interest None declared.

Open AccessThis article is distributed under the terms of the Creative Commons Attribution License which permits any use, distribution, and reproduction in any medium, provided the original author(s) and the source are credited.

\section{References}

1. Andrews N, Miller E, Grant A, Stowe J, Osborne V, Taylor B (2004) Thimerosal exposure in infants and developmental disorders: a retrospective cohort study in the United Kingdom does not support a causal association. Pediatrics 114(3):584-591

2. Bayley N (1993) Manual for the Bayley Scales of Infant Development, 2nd edn. The Psychological Corporation, San Antonio

3. CDC (2003) Whole blood lead, cadmium and mercury determined using inductively coupled plasma mass spectrometry, DLS method code: 2003-01/OD. CLIA methods. Centers for Disease Control and Prevention, Atlanta, GA

4. Centers for Disease Control and Prevention (2004) Recommended childhood and adolescent immunization schedule-United States, 2004 Jan-Jun [online]. Available from URL: http://www.cdc.gov/ $\mathrm{mmwr} / \mathrm{preview} / \mathrm{mmwrhtml} / \mathrm{mm} 5301-$ Immunizationa $1 . \mathrm{htm}$ [Accessed 2004 Jan 12]

5. Ekstrand J, Nielsen JB, Havarinasab S, Zalups RK, Söderkvist $P$, Hultman P (2010) Mercury toxicokinetics - dependency on strain and gender. Toxicol Appl Pharmacol 243(3):283-291

6. Grandjean P, Satoh H, Murata K, Eto K (2010) Adverse effects of methylmercury: environmental health research implications. Environ Health Perspect 118(8):1137-1145

7. Grandjean P, Weihe P, White RF, Debes F, Araki S, Yokoyama K, Murata K, Sørensen N, Dahl R, Jørgensen PJ (1997) Cognitive deficit in 7-year-old children with prenatal exposure to methylmercury. Neurotoxicol Teratol 19(6):417-428

8. Heron J, Golding J, ALSPAC Study Team (2004) Thimerosal exposure in infants and developmental disorders: a prospective cohort study in the United Kingdom does not support a causal association. Pediatrics 114(3):577-583

9. Jedrychowski W, Jankowski J, Flak E, Skarupa A, Mroz E, Sochacka-Tatara E, Lisowska-Miszczyk I, Szpanowska-Wohn A, Rauh V, Skolicki Z, Kaim I, Perera F (2006) Effects of prenatal exposure to mercury on cognitive and psychomotor function in one-year-old infants: epidemiologic cohort study in Poland. Ann Epidemiol 16(6):439-447

10. Jedrychowski W, Perera FP, Jankowski J, Mrozek-Budzyn D, Mroz E, Flak E, Edwards S, Skarupa A, Lisowska-Miszczyk I (2009) Very low prenatal exposure to lead and mental development of children in infancy and early childhood: Krakow prospective cohort study. Neuroepidemiology 32(4):270-278

11. Joint Statement issued by the AAP and the PHS in July 1999 "established the goal of removing the vaccine preservative thimerosal as soon as possible from vaccines routinely recommended for infants." from http://www.vaccinesafety.edu/AAFP-AAP-ACIPthimerosal.htm [accessed 2012 Jan 12]

12. Kelly YJ, Watt RG, Nazroo JY (2006) Racial/ethnic differences in breastfeeding initiation and continuation in the United Kingdom and comparison with findings in the United States. Pediatrics 118(5): e1428-e1435

13. Lederman SA, Jones RL, Caldwell KL, Rauh V, Sheets SE, Tang D, Viswanathan S, Becker M, Stein JL, Wang RY, Perera FP (2008) Relation between cord blood mercury levels and early child development in a World Trade Center cohort. Environ Health Perspect 116(8):1085-1091

14. Marques RC, Dórea JG, Bernardi JV, Bastos WR, Malm O (2009) Pre- and post-natal mercury exposure, breastfeeding and neurodevelopment during the first five years. Cogn Behav Neurol 22:134-141

15. Marques RC, Dórea JG, Bernardi JV (2010) Thimerosal exposure (from tetanus-diphtheria vaccine) during pregnancy and neurodevelopment of breastfed infants at 6 months. Acta Paediatr 99(6):934-939

16. Myers GJ, Davidson PW, Cox C, Shamlaye C, Cernichiari E, Clarkson TW (2000) Twenty-seven years studying the human neurotoxicity of methylmercury exposure. Environ Res 83(3): $275-285$

17. Oken E, Radesky JS, Wright RO, Bellinger DC, Amarasiriwardena CJ, Kleinman KP, Hu H, Gillman MW (2008) Maternal fish intake during pregnancy, blood mercury levels, and child cognition at age 3 years in a US cohort. Am J Epidemiol 167(10):1171-1181

18. Pichichero ME, Cernichiari E, Lopreiato J, Treanor J (2002) Mercury concentrations and metabolism in infants receiving vaccines containing thiomersal: a descriptive study. Lancet 360(9347):1737-1741 
19. Pichichero ME, Gentile A, Giglio N, Umido V, Clarkson T, Cernichiari E, Zareba G, Gotelli C, Gotelli M, Yan L, Treanor J (2008) Mercury levels in newborns and infants after receipt of thimerosal-containing vaccines. Pediatrics 121(2):e208-e214

20. The European Agency for the Evaluation of Medicinal Products, Committee for Proprietary Medicinal Products. Points to consider on the reduction, elimination or substitution of thimerosal in vaccines: 2001 Apr 26; EMEA/CPMB/BWP2517/00 [on-line].
Available from URL: http://www.tga.gov.au/pdf/euguide/ bwp251700en.pdf [Accessed 2004 Jan 12]

21. Thompson WW, Price C, Goodson B, Shay DK, Benson P, Hinrichsen VL, Lewis E, Eriksen E, Ray P, Marcy SM, Dunn J, Jackson LA, Lieu TA, Black S, Stewart G, Weintraub ES, Davis RL, DeStefano F, Team VSD (2007) Early thimerosal exposure and neuropsychological outcomes at 7 to 10 years. N Engl J Med 357(13):1281-1292 